\title{
Non-surgical endodontic treatment of premolars with three root canals: a case reports
}

\author{
Salih Düzgün,, ${ }^{1}$ Ahmet Aktı, ${ }^{1}$ Hüseyin Sinan Topçuoğlu, ${ }^{1}$ Melek Hilal Kaplan² \\ 'Department of Endodontics, Erciyes University Faculty of Dentistry, Kayseri, Turkey \\ ${ }^{2}$ Department of Restorative Dentistry, Erciyes University Faculty of Dentistry, Kayseri, Turkey
}

\begin{abstract}
An accurate diagnosis of the morphology of the root canal system is a prerequisite for successful root canal treatment. Some reports reveal a very rare occurrence of all types of premolar teeth in the Turkish population. Diagnostic tools such as preoperative radiography and examination of the pulp chamber floor facilitate the location of root canal orifices. The use of magnification tools, radiography exposed at two different horizontal angles, and their careful explication are important for successful endodontic therapy. This case report presents the successful endodontic treatment of three maxillary premolar teeth with three root canals and one mandibular premolar tooth with three root canals.
\end{abstract}

Keywords: Endodontics; premolar teeth; root canal system.

$\mathrm{T}$ o perform successful endodontic therapy, it is important to know the anatomy and morphology of the root canal system. Peculiarities with possible anatomic variations may lead to failure due to insufficient instrumentation and inadequate three-dimensional obturation of the root canal system. ${ }^{[1,2]}$ Accurate radiographic examination using different horizontal angles is crucial for the endodontist to recognize the roots and root canals. Additionally, the observation of the pulp chamber anatomy during coronal access is an essential procedure for the correct clinical location of root canal orifices. ${ }^{[3]}$ The high frequency of endodontic flare-ups and failures is associated with variation in root canal morphology. The factors that can contribute to observed differences in the anatomic study include ethnicity, age, gender and study design (in vitro versus in vivo). ${ }^{[4]}$ The presence of three root canals in maxillary premolars of the Turkish population is a very rare occurrence as reported by several studies. ${ }^{[5-7]}$ The presence of three root canals in mandibular premolars of the Turkish population is also a very rare occurrence as reported by Sert et al. and Ok et al. studies. ${ }^{[7,8]}$

The use of magnification and fiber optic illumination, offers a tremendous advantage in locating and treating "extra" canals. Also the dental operating microscope (DOM), has been found to be particularly helpful. The efficient use of the DOM requires advanced training. Many endodontic procedures are performed at $10 \times$ to $15 \times$ magnification, and some require a magnification as high as $30 \times$. The skillful use of a DOM entails its use for the entire procedure from start to finish. Working in such a way requires the endodontist to possess a high level of ergonomic and visual skills. ${ }^{[9]}$

This paper reports the endodontic treatment of three cases of three-canalled maxillary premolars in different patients and the endodontic treatment of one case of threecanalled mandibular premolars in a different patient.

Correspondence: Dr. Salih Düzgün. Erciyes Üniversitesi Diş Hekimliği Fakültesi,

Endodonti Anabilim Dalı, Kayseri, Turkey.

Tel: +90 352 - 2076666 e-mail: salih_duzgun@hotmail.com

Submitted: February 22, 2016 Accepted: April 05, 2016 


\section{Case report}

Case 1-A 20-year-old male patient was referred to Department of Endodontics, Faculty of Dentistry at Erciyes University with a complaint of pain in the posterior left maxillary region for the past week. He gave a history of intermittent pain in the same region for the past three months. His medical history was noncontributory. Clinical and radiographic examination revealed a carious left maxillary second premolar (\#25), which was not tender to percussion (Figure 1A). The clinical and radiographic findings led to a diagnosis of irreversible pulpitis with normal periodontium of the \#25 necessitating endodontic therapy. Radiographic evaluation indicated an unusual anatomy of three roots in \#25 (Fig. la). The tooth was anesthetized using Ultracaine ${ }^{\circledast}$ D-S (Sanofi Aventis, Levent, İstanbul) and isolated using a rubber dam. Endodontic access was prepared using a round diamond bur No. 2 and an Endo$\mathrm{Z}$ bur (Dentsply Maillefer, Ballaigues, Switzerland) in a high-speed handpiece. The pulp chamber was flushed with $5 \%$ sodium hypochlorite $(\mathrm{NaOCl})$ to remove debris and bacteria. Separate conservative access openings were made under magnification (Dental Operating Microscope; Carl Zeiss Surgical, GmbH, Oberkochen, Germany), which provided straight-line access to each canal. Examination of the pulp chamber floor revealed three distinct orifices. Canal patency was checked with \#10 K-file (Antaeos, VDW GmbH, Munich, Germany). A working length was established with an apex locator (ProPex Pixi, Dentsply Maillefer) and confirmed by taking radiography (Fig. lb). The presence of three separate canals (one palatal and two buccal) were confirmed. Cleaning and shaping were per- formed using a crown-down technique with Reciproc R25 instruments (VDW, Munich, Germany) under abundant irrigation with $5 \% \mathrm{NaOCl}$ solution in a $5 \mathrm{~mL}$ syringe. Final irrigation was performed by $10 \mathrm{~mL} 5 \% \mathrm{NaOCl}$ solution for each canal. The root canals were dried with paper points (Maillefer, Dentsply, Ballaigues, Switzerland) and obturated using cold lateral compaction technique with gutta-percha (Dentsply Maillefer) and resin-based sealer (AH plus, Dentsply Maillefer) (Fig. lc). The coronal access cavity was restored with resin composite (3M ESPE, St Paul, MN, USA). Radiographic control one year postoperatively revealed an asymptomatic tooth without signs of periapical periodontitis (Fig. ld).

Case 2-A 20-year-old male patient was referred to the Department of Endodontics, Faculty of Dentistry at Erciyes University with a chief complaint of pain in the upper-left back tooth region for a week. His medical history was noncontributory. Clinical examination of the area of chief complaint revealed dental caries with no tenderness on percussion. Based on clinical and radiographic findings and vitality tests, a diagnosis of irreversible pulpitis in relation to the right and left maxillary first premolar (\#24) was made and endodontic therapy was planned (Fig. 2a). The \#24 was anaesthetized using Ultracaine ${ }^{\circledR}$ D-S (Sanofi Aventis) and isolated with a rubber dam. Caries was removed and the access cavity was performed. Separate conservative access openings were made under magnification (Dental Operating Microscope; Carl Zeiss Surgical), which provided straight-line access to each canal. The mesiobuccal, distobuccal, and the palatal canals were explored with a size $10 \mathrm{~K}$-file. A working length was established with an apex locator (ProPex Pixi) and confirmed by taking radi-
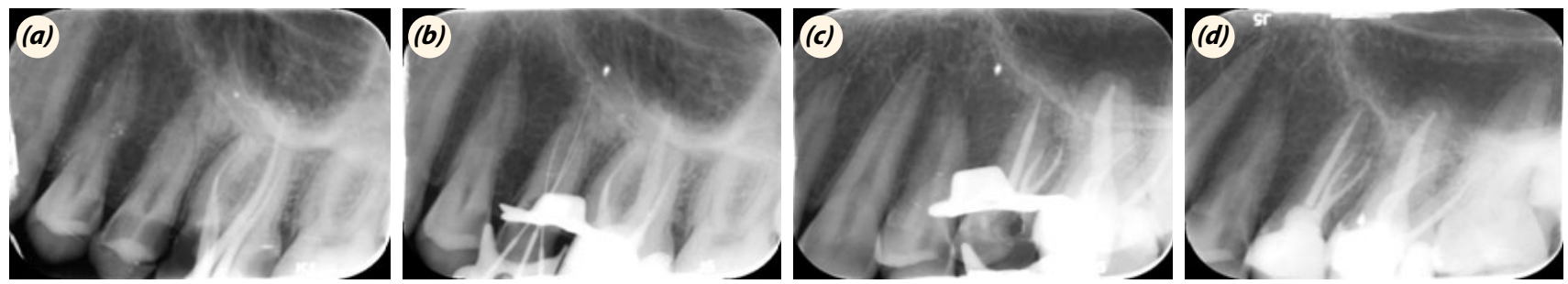

Fig. 1. Preoperative radiography (a). Length-determination radiography demonstrating three instrumented root canals (b). Radiographic control following definite obturation three root canals (c). One year follow-up radiographic control (d).
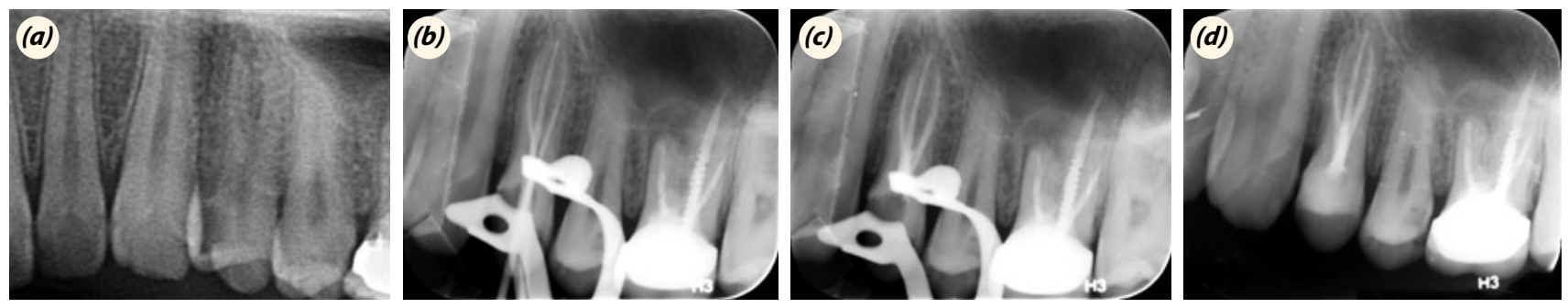

Fig. 2. Preoperative radiography (a). Length-determination radiography demonstrating three instrumented root canals (b). Radiographic control following definite obturation three root canals (c). One year follow-up radiographic control (d). 

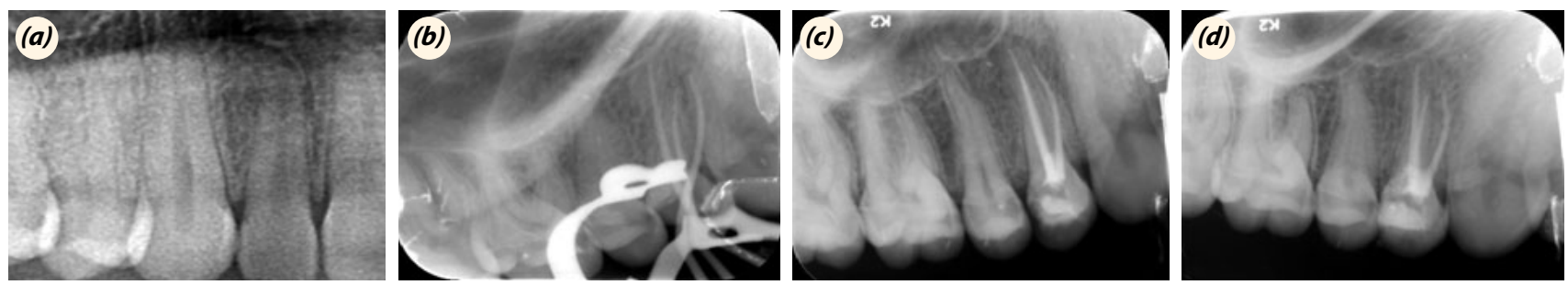

Fig. 3. Preoperative radiography (a). Length-determination radiography demonstrating three instrumented root canals (b). Radiographic control following definite obturation three root canals (c). One year follow-up radiographic control (d).

ography (Fig. 2b). Cleaning and shaping were performed using with Reciproc R25 instruments under abundant irrigation with $5 \% \mathrm{NaOCl}$ solution. All canals were enlarged to the size Reciproc R25. Final irrigation was done with $10 \mathrm{ml} 5 \% \mathrm{NaOCl}$ and the root canal space was obturated with gutta-percha and resin sealer (AH Plus, Dentsply) by lateral condensation (Fig. 2c). The coronal access was restored with resin composite (3M ESPE). Radiographic control one year postoperatively revealed asymptomatic tooth without sign of periapical periodontitis (Fig. 2d).

Case 3- A 23-year-old female patient reported to the Department of Endodontics, Faculty of Dentistry at Erciyes University, with a chief complaint of pain in the upperright back tooth region for a week. Her medical history was noncontributory. Clinical examination of the area of chief complaint revealed dental caries with no tenderness on percussion (Fig. 3a). Based on clinical and radiographic findings and vitality tests, a diagnosis of irreversible pulpitis in relation to the right maxillary first premolar was made and endodontic therapy was planned. Endodontic treatment was performed similarly to the endodontic treatment of Case 1 (Fig. 3b, c). Radiographic control one year postoperatively revealed asymptomatic tooth without sign of periapical periodontitis (Fig. 3d).

Case 4- A 22-year-old female patient was referred to the Department of Endodontics, Faculty of Dentistry at Erciyes University by a dental practitioner. The reason for referral, as stated by her general dentist, was complex root canal anatomy. Clinical and radiographic examination revealed that treatment was begun by her general dentist when she came to our department (Fig. 4a). Endodontic therapy was planned. Endodontic treatment was performed similarly to endodontic treatment of Case 1 (Fig. 4b). Radiographic control one year postoperatively revealed asymptomatic tooth without sign of periapical periodontitis (Fig. 4c).

\section{Discussion}

Clinically, precise three-dimensional determination of the internal structure of teeth, their form and number of root canals is a challenge. Each endodontic treatment is unique due to the high variability of the root canal system. ${ }^{[10]}$ Maxillary premolar teeth usually have one or two canals. The presence of three root canals in maxillary premolars of the Turkish population is a very rare occurrence as reported by several studies. ${ }^{[5-7]}$ Ok et al ${ }^{[7]}$ revealed that the incidence of three-canalled maxillary first premolars and second premolars in the Turkish population was $1.2 \%$ and $0.3 \%$ respectively. However, Calişkan et al ${ }^{[5]}$ showed that it has been shown not to be found three-rooted first and second premolars in the Turkish population

Mandibular premolars usually have one root and one canal. However, two to four canals have also been reported. ${ }^{[1,12]}$ Ok et al. ${ }^{[7]}$ revealed that the incidence of threecanalled mandibular first premolars and second premolars in the Turkish population was $0.06 \%$ and $0.2 \%$ respectively. On the other hand, Calişkan et al. ${ }^{[5]}$ showed that the incidence of three-rooted mandibular first and second premolars in the Turkish population was $5.66 \%$ and $0.00 \%$ respectively.

A third canal should be suspected clinically when the pulp chamber does not appear to be aligned in its expected buccopalatal relationship. If the pulp chamber appears to deviate from normal configuration and seems to
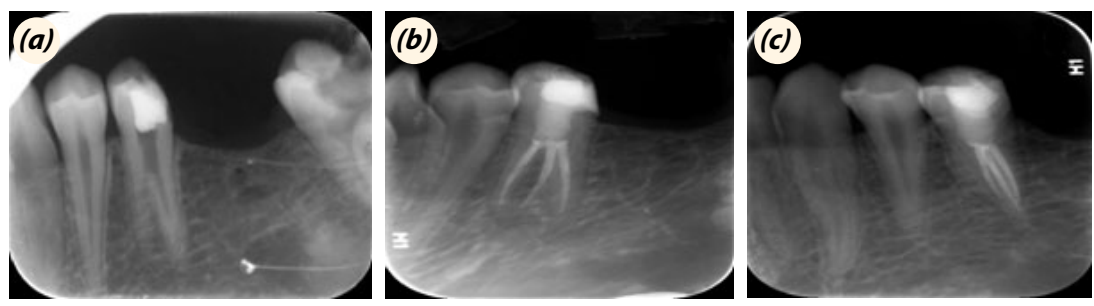

Fig. 4. Preoperative radiography (a). Radiographic control following definite obturation three root canals (b). One year follow-up radiographic control (c). 
be either triangular in shape or too large in a mesiodistal plane, more than one root canal should be suspected. ${ }^{[13]}$ The endodontic treatment of three cases of three-canalled maxillary premolars in different patients and the endodontic treatment of one case of three-canalled mandibular premolar in a different patient were presented in this paper.

Preoperative radiographs are used to identify anatomical alterations of the root canal system. The analysis of the anatomical aspects of pulp chamber roof can also help in identifying these internal variations thus, facilitating the proper location of all root canals. ${ }^{[12,14-16]}$ At least two radiographs, one right angle and the second at a $15^{\circ}$ to $20^{\circ}$ angle mesial or distal from the horizontal long axis of the root, are required to reliably diagnose more than one root or root canal system. ${ }^{[11]}$ Angled radiographies were taken for easily locating root canals in these presented cases.

A general guideline for the identification of a threerooted maxillary premolar on a straight-on preoperative radiograph is if the mesial-distal width of the mid-root image appears equal to or greater than the mesial-distal width of the crown image, then the tooth most likely has three canals. This guideline acts as a good visual clue, but is not absolute. Slight modification of the access cavity is required to locate the canal orifice in teeth with complex anatomy. ${ }^{[17]}$

A T-shaped outline to the access cavity is recommended to locate the root canal orifices in three-rooted maxillary premolars. Bilateral occurrence of complex root canal anatomy is rare, but we should always look for the anomalies in other teeth in the same patient. In this case also, the radiograph of right maxillary posterior region revealed the presence of three roots in right maxillary second premolar, hence the bilateral presence of the anomaly. ${ }^{[18]}$

The introduction of magnification loupes and DOMs has revolutionized the practice of endodontics. The advantages of using DOM for conventional endodontics include enhanced visualization of root canal disorders, which enables the clinician to investigate the root canal system and to clean and shape it more efficiently. ${ }^{[9]}$ For these reasons, it was preferable to use DOM in the presented cases.

Optimum opening of the access cavity is absolutely necessary. During the initial placement of scouting files (hand K-files \#6, 8, or 10) in the main canal, an obstruction may be encountered halfway and the file may deflect to the buccal or lingual before it travels any further. This may indicate a canal division. Thereafter, it is important to develop a sense of tactile feel and direction with appropriately precurved scouting files to detect the bi/trifurcation when working with the DOM. One can also see the hypochlorite bubbling in the extra canal, marking its presence (champaign bubbling test). Sometimes, dyes or transillumination may be helpful in locating additional canals. ${ }^{[19]}$

\section{Conclusion}

Although the incidence of maxillary and mandibular premolar teeth with three root canals is rare, each case should be examined meticulously, clinically, and radiographically to identify root canals.

Conflict of interest: None declared.

\section{References}

1. Ferreira CM, de Moraes IG, Bernardineli N. Three-rooted maxillary second premolar.J Endod 2000;26:105-6. Crossref

2. Low D. Unusual maxillary second premolar morphology: a case report. Quintessence Int 2001;32:626-8.

3. Barros DB, Guerreiro Tanomaru JM, Tanomaru-Filho M. Root canal treatment of three-rooted maxillary second premolars: report of four cases. Aust Endod J 2009;35:73-7.

4. Sert S, Bayirli GS. Evaluation of the root canal configurations of the mandibular and maxillary permanent teeth by gender in the Turkish population. J Endod 2004;30:3918. Crossref

5. Calişkan MK, Pehlivan Y, Sepetçioğlu F, Türkün M, Tuncer SS. Root canal morphology of human permanent teeth in a Turkish population.J Endod 1995;21:200-4. Crossref

6. Kartal N, Ozçelik B, Cimilli H. Root canal morphology of maxillary premolars. J Endod 1998;24:417-9. Crossref

7. Ok E, Altunsoy M, Nur BG, Aglarci OS, Çolak M, Güngör E. A cone-beam computed tomography study of root canal morphology of maxillary and mandibular premolars in a Turkish population. Acta Odontol Scand 2014;72:701-6.

8. Sert S, Aslanalp V, Tanalp J. Investigation of the root canal configurations of mandibular permanent teeth in the Turkish population. Int Endod J 2004;37:494-9. Crosssef

9. Carr GB, Murgel CA. The use of the operating microscope in endodontics. Dent Clin North Am 2010;54:191-214.

10. Soares JA, Leonardo RT. Root canal treatment of threerooted maxillary first and second premolars--a case report. Int Endod J 2003;36:705-10. Crossref

11. Cleghorn BM, Christie WH, Dong CC. The root and root canal morphology of the human mandibular first premolar: a literature review. J Endod 2007;33:509-16. Crossref

12. Cleghorn BM, Christie WH, Dong CC. The root and root canal morphology of the human mandibular second premolar: a literature review. J Endod 2007;33:1031-7. Crossref

13. Al-Fouzan KS. The microscopic diagnosis and treatment of a mandibular second premolar with four canals. Int Endod J 2001;34:406-10. Crossref

14. De Moor RJ, Calberson FL. Root canal treatment in a mandibular second premolar with three root canals. J En- 
dod 2005;31:310-3. Crossref

15. Awawdeh LA, Al-Qudah AA. Root form and canal morphology of mandibular premolars in a Jordanian population. Int Endod J 2008;41:240-8. Crossref

16. Nallapati $S$. Three canal mandibular first and second premolars: a treatment approach. J Endod 2005;31:474-6.

17. Arisu HD, Alacam T. Diagnosis and treatment of three- rooted maxillary premolars. Eur J Dent 2009;3:62-6.

18. Chauhan R, Singh S. Endodontic management of threerooted maxillary second premolar in a patient with bilateral occurrence of three roots in maxillary second premolars. J Clin Exp Dent 2012;4:317-20. Crossref

19. Nallapati S, Glassman G. Use of ophthalmic dye in root canal location. Endodontic practice 2004;15:21-6. 